\title{
The Negligence Standard: Political not Metaphysical
}

\author{
JOHNGARDNER *
}

INSTITUTIONAL ACTIONS, ORDINARY REASONS

My title echoes that of a famous article by John Rawls. ${ }^{1}$ But the main distinction that I will be drawing and exploring in this lecture is not the one that Rawls had in mind. Rawls sought to isolate, among all valid reasons for action, those that are suitable to guide and assess the use of governmental, or perhaps more broadly institutional, power. He aimed to identify reasons that have a proper place, as he sometimes put it, in 'public justification'. The hallmark of public justification, as Rawls saw it, is that it does not cleave to any particular 'conception of the good' or 'comprehensive doctrine'. Rather, it has ecumenical

* [Until 30.09.2016:] Professor of Jurisprudence, University of Oxford. [From 01.10.2016:] Senior Research Fellow, All Souls College, Oxford. This is the revised text of the 45th Chorley Lecture delivered at the London School of Economics on 21 June 2016. I received many useful comments and criticisms in conversations after the lecture. I also benefited from discussion of an earlier draft at the University of Edinburgh Department of Philosophy, and from discussion of the wider topic at a conference at the University of Birmingham School of Law. Particular thanks (but no assignment of responsibility) to Arash Abizadeh, Leo Boonzaier, Jamie Dreier, Kathryn Lindeman, Ulrike Heuer, Ori Herstein, Timothy Macklem, Mihaela Popa, Prince Saprai, Geoff SayreMcCord, Alexandra Whelan, and most especially (for detailed written comments) Matthew Chrisman and James Penner.

1 'Justice as Fairness: Political not Metaphysical', Philosophy \& Public Affairs 14 (1985), 223. 
appeal across a wide range of such conceptions, namely the ones that Rawls dubbed 'reasonable'. ${ }^{2}$ Rawls thought that this ecumenical appeal made public justification somehow less metaphysical than other kinds of justification. I have never been sure what he meant. ${ }^{3}$ Maybe he was using the word 'metaphysical' in what might be called the 'Glastonbury' sense, to mean something like 'mystical'. Maybe he hoped to demystify the theory of sound governmental or institutional action by demerging or abstracting it from the theory of sound action more generally. If that was his ambition, history has not smiled upon him. There is little in contemporary philosophy that more resembles an esoteric new age teaching than the idea of a purely 'political' theory of politics, a 'political liberalism', of the kind that Rawls bequeathed to us in his later work. ${ }^{4}$

As this remark already reveals, I am not among those who regard governmental agents as inhabiting a world apart from the rest of us. Governmental agents answer to all valid reasons for action, just like you and me. If some claimed reason for action could never possibly contribute to the justification of what a governmental agent does, then it is not a valid reason for action and cannot contribute to the justification of what anyone does. Political morality, to put it another way, is just ordinary morality as it bears on the circumstances in which certain agents (certain officials and institutions) find themselves. These circumstances may seem a world apart at first sight. Few of us have vast armies to command, multi-million-pound healthcare budgets to spend, or a succession of strangers parading before us who face losing

${ }^{2}$ For a short recapitulation of these ideas, see Rawls, 'The Idea of Public Reason Revisited', University of Chicago Law Review 64 (1997), 765 at 786. Here Rawls speaks of 'comprehensive doctrines' where, in 'Justice as Fairness', n1 above, he had spoken of 'conceptions of the good'.

${ }^{3}$ His attempt to explain appears in 'Justice as Fairness', n1 above, 238-40.

4 See my 'The Mysterious Case of the Reasonable Person', University of Toronto Law Journal 51 (2001), 273. 
their liberty or their children on our say-so. Yet still these are, in the final analysis, but large-stakes examples of the same kind of responsibilities that we all have as friends, employers, teachers, neighbours, and so on. Public or private, individual or collective, personal or institutional, in law or in love, in parliament or in the supermarket, all valid reasons for action count.

It is true that they may count, among other things, in the assignment of responsibilities. It is true that when we have responsibilities we have reasons to concentrate on some reasons for action at the expense of others in connection with our own actions. Such playing up and playing down of reasons is the normal business of all rational life, or at least all human rational life - for parents and volleyball teams as much as for police officers and constitutional courts. Only rarely should one person attempt to attend even-handedly to all the applicable reasons at once in her reasoning. Apart from anything else, doing so would often be counterproductive. Focusing one's attention on a subset of the applicable reasons, or even relying on some simplified proxy reasons that marshal and conceal the underlying melée of applicable reasons, is often a better policy, with a lower error rate. That much was pointed out by Rawls himself in earlier work. ${ }^{5} \mathrm{He}$ used it to explain the rational appeal of certain rules, including responsibility-assignment rules, that lie at the heart of certain social practices. It is, however, a long way from this early Rawlsian insight to the later Rawlsian thesis that the theory of sound government (sound judging, sound legislating, sound constitution-making, etc.) can be demerged or abstracted from the theory of sound action more generally. The earlier Rawlsian argument reveals a set of reasons that are relevant to the assignment of all responsibilities if they are relevant to the assignment of any. It has no special application to the assignment of governmental or institutional responsibilities.

${ }^{5}$ Rawls, ‘Two Concepts of Rules', Philosophical Review 64 (1955), 3. 


\section{ASSIGNABLE RESPONSIBILITY}

The idea that there might be reasons to assign different responsibilities to different agents brings me closer to the topic of my lecture. It does not bring me, just yet, to the negligence standard. But at least it brings me to the conceptual space within which reflection on the negligence standard takes place.

Some people think, as I once thought, ${ }^{6}$ that there are two senses of 'responsibility' which are both such that responsibility can be assigned differentially to different agents. They are sometimes called, following Joel Feinberg, the 'prospective' sense and the 'retrospective' sense. ${ }^{7}$ When we talk of assigning responsibilities (plural), we are generally thinking of things that are, at the time when the responsibility arises, yet to be done. We are asking who will be the one to do those things, or at least see to it that they are done. When we talk of assigning responsibility (singular), by contrast, we are often thinking of things that were already done, or will already have been done, by the time the responsibility arises. We are asking who will be the one to face the music or pick up the pieces when the things that were supposed already to have been done were not done.

We all know that the prospective and the retrospective judgments can come apart. I may end up with retrospective responsibility for failures that fell outwith the prospective responsibilities that belonged to me at the time of the failure. Suppose that I am the successor in post of the person who had some prospective responsibility. I am the new Home Secretary or the new Data Protection Officer. My predecessor was the one

6 Gardner, 'Hart and Feinberg on Responsibility' in Matthew H. Kramer, Claire Grant, Ben Colburn, and Antony Hatzistavrou (eds), The Legacy of H.L.A. Hart: Legal, Political, and Moral Philosophy (Oxford: Oxford University Press 2008), 121 at 133.

7 Feinberg, 'Responsibility for the Future', Philosophy Research Archives 14 (1998), 93. 
who was supposed to have made sure the report was delivered on time, but it wasn't done. Now I am the one who is left to face the music and pick up the pieces. Such cases may lead one to think, as I used to think, that we are already dealing with two distinct senses of the word 'responsibility', namely a prospective sense and a retrospective sense. My predecessor was responsible in the prospective sense for the delivery of the report; yet I am responsible, in the retrospective sense, for its non-delivery.

There is another way to think about such cases, however, which I now think is preferable. To assign restrospective responsibility is to reassign prospective responsibility retroactively. When I take over a role from some delinquent predecessor and have to face the music for what that person did in the same role, the original (prospective) responsibility has become mine by reassignment. I inherited it as part of the role. Never mind that I personally wasn't around last month to have fulfilled it, at the time when it called for fulfillment. When I say 'never mind', I mean that we shouldn't think that there is any conceptual obstacle to the retroactive reassignment. We shouldn't think that it is blocked by 'ought implies can' or some similar luck-proofing doctrine. Life would be so much less awkward if only it were true that, whenever I ought to have done something, I was already at the time in a position to have done it and to have known that it was mine to do. Alas, the human condition is not so obliging. Yet the word 'alas' here reveals that we should worry about the retroactive reassignment in another way. The reassignment can be awkward for the person on the receiving end of it. Sometimes it might even be unfair. When it is unfair, we need a suitably strong case for doing it. Notice that this way of thinking about what is going on already concedes my main point. Prospective responsibility is conceptually capable of being retroactively reassigned and the question in any given case is only whether there is a suitably strong case for reassigning it, even at the price of some possible unfairness to the reassignee. 
My conversion to this revised way of thinking about roletransfer cases is allied to my coming to understand better the implications of a thesis that I have elsewhere labelled the 'continuity thesis'. ${ }^{8}$ According to the continuity thesis, when I fail to do what I have a duty to do, I acquire without further ado a fallback duty to do the next best thing - a duty, so far as it can still be done, to make up for my failure. Whatever reasons I failed to conform to when I failed to do my duty still await my conformity, and they are what justify and give shape to my new duty. The expression 'next best thing' in my formulation of the continuity thesis means, therefore, the next best way of conforming to the very same reasons. Since the reasons stay the same, one may be tempted to think that the fallback duty is just the original duty in a new guise. ${ }^{9}$ But that is not so: duties are individuated according to the actions that they are duties to perform. A duty to perform a different action is a different duty. Responsibilities, however, are individuated otherwise. Alongside rights, ${ }^{10}$ they belong to the apparatus for explaining why I have whatever duties I have. They are individuated at the level of the reasons for my duties. I have a responsibility inasmuch as a certain reason or set of reasons is mine to conform to. The relevant set of reasons need not be definitely specified; it may be an indefinitely-specified set such as 'any reasons that bear, when the time comes, on whether and when the lights are to be switched off.' Whether definitely or indefinitely specified, however, the same reasons are reasons for several duties if they are reasons for any. If they are reasons for an original duty (e.g. a duty to switch off the lights, or to see to it that they are switched off, when the

${ }^{8}$ Gardner, 'What is Tort Law For? Part 1. The Place of Corrective Justice', Law and Philosophy 30 (2011), 1 at 33.

9 This is the way that Ernest Weinrib presents it in The Idea of Private Law (Cambridge, Mass.: Harvard University Press 1995), 135.

${ }^{10}$ See Joseph Raz, 'On the Nature of Rights', Mind 93 (1984), 194 esp 211-2 where the relationship between rights and responsibilities is sketched. 
last person leaves) then, by the continuity thesis, they are also reasons for a fallback duty (e.g. a duty to go back and switch the lights off later if the lights weren't switched off at the right time). We should think of these two duties, it seems to me, as two payoffs or incidents of one and the same responsibility. So when someone puts it to you that you were responsible for turning off the lights (prospective) and infers that you are responsible for the lights having been left on (retrospective) we should regard them as offering, essentially, two formulations of one and the same point. They are asserting what we might most simply call your responsibility for the lights. Your responsibility for the lights is essentially diachronic: if the lights still being on isn't your responsibility, their being turned off wasn't any responsibility of yours; and if the lights still being on is your responsibility, their being turned off must have been a responsibility of yours - even if that means that we have just retroactively made it so. ${ }^{11}$

Not all situations in which someone is singled out to face the music or pick up the pieces in respect of another's failures fit this pattern of retroactive re-assignment. Employers, for example, do not have any responsibility assigned to them retroactively when they have to pay for the failures of their employees. Rather they already had a second-order responsibility to see to it that their employees fulfilled their first-order responsibilities as employees. The employer's responsibility here is not the acquisition of the employee's responsibility but the continuation of the employer's own. So there is nothing retroactive going on. At least that is one possible analysis. ${ }^{12}$ Another possible analysis is that employers are

${ }^{11}$ I am here implicitly rejecting the distinction drawn by Andrew Khoury in his 'Synchronic and diachronic responsibility', Philosophical Studies 165 (2013), 735. Unfortunately my quarrel with Khoury cannot be developed here.

12 The analysis is often discussed, and usually rejected as out of keeping with the law, under the heading of culpa in eligendo/in vigilando: negligence in the selection or supervision of the employee. See e.g. Paula Giliker, Vicarious Liability in Tort: A Comparative Perspective (Cambridge: Cambridge University 
akin to insurers. Possibly employees do not have a second-order responsibility to see to it that their employees fulfil their firstorder responsibilities as employees any more than my motorinsurance company has a second-order responsibility to see to it that I fulfil my first-order responsibilities as a driver. True, the insurance company has to pay out when I cause damage by my bad driving. But that is not because responsibility for the avoiding-or-causing of the damage has been retroactively assigned to them. All that has been assigned to them is a fresh responsibility, to pay for the damage, that arose de novo when I failed in my responsibility not to cause that damage. That fresh responsibility was assigned to the insurer by the contract of insurance. While there is an assignment of responsibility here, there is nothing retroactive about it. It is not that the insurer is now held to have been responsible for avoiding the damage, hence responsible for having done the damage, hence responsible for picking up the pieces now that the damage is done. No, the insurer's responsibility arises only at the pick-up-the-pieces stage, and it is not a responsibility for the damage, exactly, but only a responsibility for paying for the damage (i.e. for 'the damages'). Might it not be thus with employers too?

Although the differences between these various situations are fascinating, my immediate interest is in a feature that all of them share. They all highlight that responsibility, as we have been discussing it up to now, is the kind of thing that can be assigned or, if you prefer, allocated. That much is true whether you think that we have so far been discussing two different senses in which an agent can be responsible, or only one sense. To simplify our discussion I will generally foreground judgments of responsibility of the kind that Feinberg would have called prospective. I will presuppose that the deed is yet to be done. But with or without

Press 2010), 231-4. In my version, however, there is no mention of any culpa on the employer's part. That there can be no responsibility without culpa is the main proposition that I attempt, in this lecture, to deny. 
that restriction, an agent's responsibility, as we have been discussing it up to now, is the kind of thing that can be augmented or curtailed by someone's exercising a normative power over it. Sometimes I take responsibility for something. Responsibility is here assigned to me by my own consent or undertaking. In other cases, I am given responsibility or, in a different idiom, made responsible. Here the responsibility is assigned to me by an exercise of another's authority.

It is important not to conclude, from the fact that responsibility is assignable, that we have none of it without an act of assignment. Many of our responsibilities are ours simply because of the value of our having them, without our having taken them on and without anyone having given them to us. Parental responsibility, for example, descends upon parents without the exercise, by themselves or by others, of any normative powers. There is normally no live question of whether I consented to be a parent, or undertook to do it, etc. Parents have parental responsibility just by virtue of being parents. The question of assignment arises only when parents begin to consider leaving the children with granny for the weekend or signing them into a play scheme for the day, or (more radically) when someone begins to think of adoption, fostering, making the children wards of court, etc. The question of assignment arises, in other words, only when we begin to think about giving parental responsibility (in whole or in part, substitutively or supplementally) to people other than the parents.

The parenthetical words here are important. A tempting objection to the idea that responsibility is assignable is that sometimes I have a logically irreplaceable role in the fulfilment of my own responsibilities. ${ }^{13}$ Only I can keep the promise I made, only I can atone for my own wrongs, etc. How can these

${ }^{13}$ I thank Arash Abizadeh for pressing me on this point. Arash also wanted me to think about inalienable duties not to murder, rape, torture, etc. My remarks in the text can also be applied, with some modifications, to these. 
responsibilities possibly be re-assigned? Answer: these are the duties, not the responsibilities. True, these particular actions, and hence these particular duties of mine, cannot by their natures be proxied. ${ }^{14}$ But other people can be given, or can take, supplemental responsibility in respect of my performance of them (e.g. it can be their job to encourage me or compel me to do my duty). And other people can be given, or can take, supplemental or substitutive responsibility in respect of the performance of certain fallback actions (e.g. making it their job to mop up after my failures). When I say 'can be given' or 'can take' here I mean the 'can' to be read conceptually. I leave open the desirability of such assignments, and (a different matter) the effectiveness of attempts to bring them about. It is no part of my thesis that responsibility is always effectively re-assigned when someone attempts to re-assign it, let alone that attempting to reassign it would always, or indeed often, be a good idea. My thesis is only that responsibility, as we have been discussing it up to now, is the kind of thing, the taking or giving of which is an intelligible proposal and an imaginable undertaking.

The taking and giving of responsibility are both of great importance in the law, the giving more fundamentally than the taking. The law claims, by its authority, to make each of us responsible for some things and not for others. ${ }^{15}$ We may think that these authority-claims are ill-founded, at least in some cases. The law, we may think, is wrong to the point of illegitimacy in the way in which it makes accomplices responsible for certain acts of their principals, or in the way in which it limits the responsibility of company directors for some acts of their

14 For more on proxyability, see Sanford Kadish, 'Complicity, Cause and Blame: A Study in the Interpretation of Doctrine' California Law Review 73 (1985), 323.

15 The broader idea that law claims authority is most often associated with Joseph Raz. A useful discussion and defence is Bas van der Vossen, 'Assessing Law's Claim to Authority', Oxford Journal of Legal Studies 31 (2011), 481. 
companies, or in the way in which it allows insurance to lighten the responsibility-burden of tortfeasors. We may think, in other words, that the legal position in these or similar cases is so misguided as to cast doubt on the moral effectiveness of the law's purported exercise of authority in them. We may even be anarchists who think that all the law's purported exercises of authority are morally ineffective, and so should be ignored, subverted, or derided rather than adhered to. But these objections, you will notice, are only to the moral effectiveness of some or all of the law's purported assignments of responsibility. They do not deny, indeed they presuppose, that responsibility is the kind of thing that could conceivably be assigned. Assigning responsibility by authority, consent, undertaking, disclaimer, etc. may not always succeed, but it is no category mistake.

\section{BASIC RESPONSIBILITY}

Except when it is. At this point we need to distinguish responsibility in the sense or senses we have just been discussing (I'll call it 'assignable responsibility') from responsibility in a very different, although closely related, sense, which I like to call 'basic responsibility'. ${ }^{16}$ Basic responsibility is what it sounds like. It is an ability. More fully, it is the ability and propensity to have and to give self-explanations in the currency of reasons. The ability and the propensity are but two sides of the same coin. As beings who are able to respond to reasons we cannot avoid being disposed to respond to them. There is nowhere to hide from them. As Jean Renoir expressed the point nicely in La Règle du Jeu: 'sur cette terre il y a quelque chose d'effroyable, c'est que

16 See Gardner, Offences and Defences (Oxford: Oxford University Press 2007), ch 9. Basic responsibility as I explained it was studied further by Angela Smith in 'Responsibility as Answerability', Inquiry 58 (2015), 99-126. I have benefited greatly from reading Smith's work on this point and several others. 
tout le monde a ses raisons.' 17 And having one's reasons is only the start. One not only responds to reasons in what one thinks, feels, wants, and does. One also responds to them again in telling the story - to oneself or others - of what one already thought, felt, wanted, and did. In saying this I do not doubt that in selfexplanation people often conjure up rationalisations, making themselves look or feel better in the telling than their original reasons would have allowed them to look or feel. Of course they do. This is but one among many tragic aspects of life as a basically responsible agent. What else would one crave, as a being with the ability and propensity to respond to reasons, than to have had better reasons than, alas, one had? This already shows that basic responsibility is by no means a kind of success with reasons. It does not entail that one is wise, sensitive, or even competent in one's grasp or use of reasons. It connotes no skill and no virtue of character. ${ }^{18}$ We all have our reasons, to be sure, but it doesn't mean we all have good or adequate or even valid reasons. Often we don't; we take things to be reasons which in fact are not, or we give some reasons more weight than they are capable of bearing. None of that is inconsistent with our basic responsibility. The question of how well we respond to reasons arises only because, and when, we are basically responsible.

Basic responsibility, I suggest, cannot be assigned or allocated by anyone. There is no normative power, by the exercise of which anyone can add to or subtract from it. That is not because it is impossible for any of us not to have it. Some of us lack it altogether. Well, actually, that depends on who counts as 'us'.

${ }^{17}$ La Règle du Jeu (Paris: Gaumont 1939) at 20:16.

18 There is also a virtue of character called 'responsibility'. Aristotle called it phronesis, often translated as 'practical wisdom'. It is a kind of master-virtue. 'It is not possible to have any moral virtue without phronesis, nor to have phronesis without any [other] moral virtue,' says Aristotle at NE $1144^{\mathrm{b}} 30-34$. Although the concept is closely bound up with those under discussion, for reasons of space I will not be saying any more about the virtue of responsibility here. 
But assuming we mean 'human beings', we might doubt the basic responsibility of very young children, those with advanced forms of dementia or severe mental illnesses, and those in comas. Surely basic responsibility is entirely lacking in at least some such cases? Yes, and that is already a matter of regret. Human beings ought to be answerable to reasons. That is part of their human ergon, to use the Aristotelian term, sometimes translated as 'function' but perhaps better as 'destiny'. ${ }^{19}$ With young children, the expectation is usually that they will sooner or later come to be answerable to reasons; with the others there may be the hope, however vain, that they might. With the rest of us, however, the conditions of basic responsibility are typically met. Typically we are responsible for our actions, and for our thoughts, feelings and wants. Typically, but not invariably. Being basically responsible doesn't mean being basically responsible for all your actions, thoughts, feelings, and wants. There are exceptions. Here is one. If I have a kind of severe obsessive-compulsive disorder (OCD) that propels me to wash my hands every few minutes, that may affect my basic responsibility for washing my hands every few minutes, and perhaps for some things that I failed to do while I was washing my hands. But it doesn't affect my basic responsibility for forgetting the groceries or distracting the bus driver, when my OCD did not play any part in the story.

Now OCD can often be treated, or, failing that, managed. ${ }^{20}$ Those who suffer from it can be restored to basic responsibility in respect of the class of actions into which their OCD once propelled them, or from which it once distracted them. So I am obviously not denying that basic responsibility can be

${ }^{19} N E 1097^{\mathrm{b}} 22-1098^{\mathrm{a}} 20$. I explored some implications of this idea in Law as a Leap of Faith (Oxford: Oxford University Press 2012), ch 6, and others (with Timothy Macklem) in 'Human Disability', King's Law Journal 25 (2014), 60.

20 Martin Antony, Christine Purdon, and Laura Summerfeldt (eds), Psychological Treatment of Obsessive-Compulsive Disorder: Fundamentals and Beyond (Washington DC: American Psychological Association 2007). 
deliberately conferred or restored, or indeed taken away, by a suitable human intervention. The point is only that an exercise of a normative power over the basic responsibility is not the relevant kind of human intervention. It is a category mistake to treat basic responsibility (unlike assignable responsibility) as the kind of thing that can be imposed by an exercise of authority purporting to impose it, or likewise by giving consent to having it or undertaking to have it, or by disclaiming it, etc. Should we advise the OCD-sufferer to seek relief, not from a cognitivebehavioural therapist, but from a judge or magistrate?

That is not to deny that judges have their role to play in the investigation of basic responsibility. Like assignable responsibility, basic responsibility is of great importance in the law. Every day, in the courts as in other corners of life, people are held responsible, deemed responsible, or treated as responsible. They also accept or claim responsibility. Clearly these expressions are sometimes used in connection with basic responsibility, and intelligibly so. That is because it is possible to make authoritative or otherwise binding determinations of fact such that, for certain purposes, certain propositions will be treated as true even if they are false. Propositions about basic responsibility are among them. Just as a court might declare a testator to be dead or proceed on the footing that he is dead, a court might declare a defendant to be basically responsible or proceed on the footing that she is basically responsible. The defendant may also admit or assert her basic responsibility, just as she may admit or assert her dyslexia or her forgetfulness. Things may then proceed in the law, and where the law has influence, as if these declarations, admissions, etc. were true. But it does not mean that they are true. That a testator is declared dead or treated as dead doesn't make him dead; that a defendant claims to be dyslexic doesn't make her dyslexic; that a someone is declared or conceded to be basically responsible doesn't make her basically responsible. A normative power was exercised, but it was not a normative power to make the defendant basically responsible. It was a normative power to 
permit or require the court, and others covered by the doctrine of res judicata, to proceed as if she were basically responsible even if, as all involved may know, she is nothing of the kind.

The idioms of 'holding someone responsible' and 'accepting responsibility' are in particularly widespread use, and not only in the law. The reason is not hard to see. The words are equivocal and the equivocation can be advantageous. The words can easily be heard as words of assignment, indicating that someone is being made responsible when they otherwise wouldn't be. But they can just as easily be heard as indicating a proposition that one is treating, for one or more purposes, as true. ${ }^{21}$ Sometimes it is convenient to leave it vague which of these two things one is doing in connection with responsibility. This need not be a form of concealment. It can simply be a form of economy. When I say that I 'hold you responsible' I am often trying to convey two points at once, and I want you to hear them both. I am trying to convey (a) that I regard you as basically responsible for something and (b) that I am therefore not attempting to re-assign assignable responsibility for that thing to anyone else, nor inviting you to re-assign it to anyone else. Likewise when I say that I 'accept responsibility', I may be trying to convey two things at once. I may be trying to convey (a) that I decline to contest the truth of the proposition that I am basically responsible for something, and (b) that therefore I am not attempting to re-assign assignable responsibility for that thing to anyone else, or indeed inviting you to do so. I am not trying to pass the buck.

The word 'therefore' in these explanations testifies to some connection between my being basically responsible for something and my being assignably responsible for it. What is the connection? There are several. I will mention three, themselves

21 For similar points about 'taking responsibility' see David Enoch, 'Being Responsible, Taking Responsibility, and Penumbral Agency' in Ulrike Heuer and Gerald Lang (eds), Luck, Value, and Commitment: Themes from the Ethics of Bernard Williams (Oxford: Oxford University Press 2011), s4. 
closely interconnected. First, the question of my basic responsibility arises principally in connection with the question of whether I acquitted myself in respect of some assignable responsibility. There we see one reason why my assignable responsibilities are called 'responsibilities'. It is because they are the things in respect of which I am the one who owes (to somebody, or to nobody in particular ${ }^{22}$ ) a self-explanation in the currency of reasons. To this end I need the ability to have and to provide such a self-explanation, i.e. I need to be basically responsible. And that brings us to the second connection. My basic responsibility for something is normally a condition of my assignable responsibility for that same thing. The word 'normally' is there to allow for special cases in which assignable responsibility for something is assigned to someone who lacks basic responsibility for that thing. The assignee may be someone who consents or undertakes to be treated as if she had been basically responsible. The assignee may also be someone regarding whom someone else has authority to make factual determinations, and who (thanks to such a determination) is treated as if she were basically responsible. These two cases are quite different in some ways. However they both reflect, by a roundabout route, the normal dependence of assignable responsibility upon basic responsibility. In both cases the assigning of assignable responsibility to someone means treating the assignee as if she were basically responsible. She is made responsible in one sense and that means holding her responsible, even if fictitiously or erroneously, in another sense.

But why does it mean that? That brings us to the third and deepest connection. In a way basic responsibility is the whole, the totality, of which assignable responsibility is but a special part. Ultimately, all reasons are mine to contend with, to respond to,

22 For doubts about 'nobody in particular' cases, some of them directed against my views, see R.A. Duff, Answering for Crime: Responsibility and Liability in the Criminal Law (Oxford: Hart Publishing 2007), 23-30. 
and to explain myself in terms of. As a rational being I have nowhere to hide from any of them. ${ }^{23}$ Even if a reason is such that only some other person could satisfy it (e.g. your reason to keep a promise that you made), there is always the question of what I might have done to help. In the ultimate analysis, nothing is ever 'none of my business'. Therein lies my basic responsibility. But only rarely, to repeat what I said in my opening remarks, should I attempt to attend even-handedly to all reasons at once. For, as George Eliot evocatively puts it in Middlemarch,

If we had a keen vision and feeling of all ordinary human life, it would be like hearing the grass grow and the squirrel's heart beat, and we should die of that roar which lies on the other side of silence. ${ }^{24}$

For each of us, most of the time, some reasons are to be played up and others played down. That is itself is explained by reasons; it represents the only reasonable way for us to engage, as finite beings, with the madding 'roar' of reasons (which proliferate even beyond the 'ordinary' humanistic ones foregrounded by Eliot). ${ }^{25}$ At the surface of our rationality, then, we have some things that are especially our business, and others not so much. The things that are especially our business, demarcated as clusters or ranges of reasons, are our assignable responsibilities. Unlike the non-negotiable fact of our basic responsibility - hence the inescapable hold that every reason has over us - these assignable responsibilities could in principle be augmented, curtailed, replaced, or displaced by ourselves or others.

${ }^{23}$ In particular, to reprise the theme of my introductory section, public office gives one no hiding place. See my 'Criminals in Uniform', in RA Duff, Lindsay Farmer, SE Marshall, Massimo Renzo and Victor Tadros (eds), The Constitution of Criminal Law (Oxford: Oxford University Press 2012).

${ }^{24}$ Eliot, Middlemarch (Edinburgh: William Blackwood 1871), bk 2 ch 20.

25 For expansion of the cryptic parenthetical remark, see Timothy Macklem and John Gardner, 'Value, Interest, and Well-Being', Utilitas 18 (2006), 362. 
POLITICAL V METAPHYSICAL

It has taken us a long time to reach the distinction between the political and the metaphysical, the one that I had in mind when I gave my lecture its title. Assignable responsibility belongs to politics in the widest sense of the word. It is possible, by the use of authority, consent, or other normative powers, to assign this responsibility and to re-assign it. Remember that by calling it assignable I am not saying that it is always assigned. The same kinds of reasons that can justify assigning assignable responsibility to someone can also justify their having assignable responsibility without anyone's having assigned it. You may have assignable responsibility for switching out the lights because I gave you that job, or just because you are the last one to leave and there was nobody to assign the job. As this example reminds us, there may be good policies and bad policies concerning the assignment or non-assignment of assignable responsibility. Some people may end up with too much of it and others with too little; there may be unfair distributions of it and inconvenient allocations of it and so on. It may be my responsibility to switch the lights out, since I signed out the key, even though it would have been better if you had signed out the key and thereby acquired responsibility for the lights. And as this case illustrates, the conditions of assignable responsibility may vary from occasion to occasion; one may find that sometimes one acquires or loses responsibility easily, and on other occasions only with difficulty. Such differences may be explained, and indeed justified, by pointing to the advantages of assigning responsibility on certain conditions on certain occasions, but not on other occasions. The whole organisation (and disorganisation) of our assignable responsibilities could be cast as a matter of advantage and disadvantage. Who is best doing what and seeing to what, and hence answering for what?

At least one condition, however, is less flexible. It is the basic responsibility condition. Assignable responsibility is sometimes assigned, rightly or wrongly, to people who are not basically 
responsible for whatever they are being assigned assignable responsibility for. However, it is assigned to nobody without at least the fiction of their basic responsibility for whatever they are being assigned the assignable responsibility for. No making responsible, we might say, without holding responsible. And what is more the conditions of basic responsibility, unlike some other conditions of assignable responsibility, do not respond to the advantages and disadvantages of those being the conditions. The conditions of basic responsibility are what they are and people meet them, when they do, irrespective of the appeal, the attractions, the merits, the value, the fittingness, of it being the case that they meet them. That is not to say that there is no value in their meeting them. It is an aspect of our human ergon, as I called it, that we should meet them. If we do not meet the conditions of basic responsibility, that means something is amiss with us as human beings. No explanation of what it takes to be human can omit to give a central place to the fact that humans are supposed to answer to reasons, and that even when we don't, we still ought to. In that sense basic responsibility can be thought of as a 'metaphysical' truth. It belongs, if it belongs anywhere, to an explanation of what makes human beings fit to have assignable responsibility assigned to them. Basic responsibility belongs to the relatively fixed presuppositions, if you like, of the extremely pliable politics of assignable responsibility.

\section{BASIC RESPONSIBILITY WITHOUT NEGLIGENCE}

In general, I said, we are basically responsible for our actions. How about our negligent actions? The question has a long history among lawyers, for the negligence standard has a venerable and wide-ranging role in many legal systems. The question first arises because negligent actions are by definition unintentional actions, and so are not performed for reasons. They 
are performed, rather, in the course of performing other actions that are performed for reasons. ${ }^{26} \mathrm{I}$ intentionally drive out of the side road; I thereby unintentionally, perhaps negligently, drive into the path of your car. I intentionally undertake repairs on your gas boiler; I thereby unintentionally, perhaps negligently, leave it poorly ventilated. One may wonder: How can I answer to reasons in respect of actions that I did not perform for reasons - actions, indeed, that I did not even take myself to have reasons to perform? How do those tragic actions fit into Jean Renoir's characterisation of the human tragedy?

Personally, I do not find that a very difficult question. ${ }^{27}$ As basically responsible agents we answer to reasons that we overlook as well as reasons that we attend to. That basic responsibility must be symmetrical on this front is revealed even when we think about intentional actions. I intentionally kick my neighbour's dog. Sure, I have my reasons. The dog is always bothering me and this kick, I reckon, will teach him to keep his distance. But what about all the obvious reasons not to go about kicking dogs, still less other people's dogs? Well, I didn't give those reasons any weight, or indeed any thought. In my frustration I forgot all about them and attended to just the one reason for which I acted. Does it follow that the other reasons are

26 Although not always deliberately. Getting oneself stung while instinctively trying to flap a wasp away from one's face is a good example of doing something unintentional - indeed counterintentional - in the course of doing something that is intentional but not deliberate. Timothy Macklem and I protested against a too-deliberate picture of rational agency in 'Reasons', in Jules Coleman and Scott Shapiro (eds), The Oxford Handbook of Jurisprudence and Philosophy of Law (Oxford: Oxford University Press 2002)

27 Others are more troubled. Recent examples: Larry Alexander and Kimberly Ferzan, 'Against Negligence Liability,' in Paul Robinson, Stephen Garvey, and Kimberly Ferzan, (eds.), Criminal Law Conversations (Oxford: Oxford University Press 2009) 273; Heidi Hurd, 'Finding No Fault with Negligence', in John Oberdiek (ed.) Philosophical Foundations of the Law of Torts (Oxford: Oxford University Press 2014). 
not my problem, that I do not answer to them? Far from it. If I hope to escape the harshest judgments that I might face as dogkicker, if I hope to reduce the volume of the music that I will properly face from my neighbour, from the local paper, from the RSPCA, even from the courts, I had better be able to explain why I overlooked these reasons. I had better be able to give reasons why these reasons did not occur to me or did not weigh with me. This shows how my basic responsibility extends to overlooked reasons: by extending to my explanations, in the currency of reasons, for having overlooked them. And if my basic responsibility extends this far in the case of intentional actions like dog-kicking, then why not in respect of unintentional actions like leaving your boiler inadequately ventilated or driving into the path of your car?

This, however, makes one think about a different way in which negligence might matter to basic responsibility. Could it be that I am basically responsible for unintentional actions only if they are negligent? That view is sometimes advanced. ${ }^{28}$ I want to persuade you here of its untenability. To do that I first need to tell you a little more about basic responsibility.

When we explain ourselves in the currency of reasons, we often aim thereby to justify ourselves. We hope to reveal that we had sufficient reasons to do as we did, or to think as we thought, or to feel as we felt, or to want as we wanted, and that was why we did so. But sometimes, at any rate where our actions are

28 e.g. Gideon Rosen, 'Skepticism About Moral Responsibility', Philosophical Perspectives 18 (2004), 295; George Sher, Who Knew? Responsibility without Awareness (New York: Oxford University Press 2009); Joseph Raz, 'Responsibility and the Negligence Standard', Oxford Journal of Legal Studies 30 (2010), 1. In listing these writings I am plagued by the thought that the responsibility that their authors had in mind is not my basic kind and not even their basic kind. Any debate in which responsibility-talk looms large tends to be held up for want of shared conceptual foundations. All one can do is what I have done here, namely set out one's conceptual stall and await the probable response: 'That wasn't the kind of responsibility I had in mind.' 
concerned, we lower our sights. Our self-explanatory aims are no more than excusatory. We concede that we were not justified in doing as we did, but we hope to reveal that we nevertheless did as we did on the strength of justified thinking, feeling, or wanting. Our reasons for acting were insufficient, we concede, but we had sufficient reasons for taking them to be sufficient or treating them as sufficient - either for taking them to exist when they did not, or for exaggerating their importance when they did. We were misled by credible testimony, or we were consumed with grief, or we were harassed and pestered to the point of losing our cool, etc. Such excuses are our first fallback when we lack justifications. ${ }^{29} \mathrm{I}$ am not suggesting that basically responsible people always have good or adequate or convincing excuses. I am suggesting that, lacking good justifications, they are disposed to look for good or adequate or convincing excuses, and in the process to show that they remained reason-responsive even when, in the round, they acted contrary to reason. Renoir's aphorism conveys this nicely - 'tout le monde a ses raisons' - and his film plays up the following implication in fine style. Not everyone has good, adequate, convincing, or even valid reasons for what he or she does; but everyone, every basically responsible agent, has (i) what he or she takes to be some reasons for what he or she does, and (ii) some reasons, however pathetic and unconvincing, for taking them to be reasons for doing it.

The human tragedy that Renoir has in mind is the extent to which reasons to think and feel and want can draw us, quite rationally, into rational failure at the point of action, i.e. into doing what we have no, or too little, reason to do. Or if you don't like the word 'rational', which economists have stolen from the English language to use in their own technical sense for their own nefarious ends, you can substitute the friendlier word

${ }^{29} \mathrm{I}$ am here reprising points I developed at greater length in Offences and Defences, $\mathrm{n} 16$ above, ch6. 
'reasonable', the word that Rawls chose. ${ }^{30}$ The tragedy, to put it in these friendlier terms, is that even perfect reasonableness is not enough to protect us reliably against doing something seriously unreasonable. All of us are vulnerable to being lured by thoughts, feelings and wants that we had ample reason to harbour into doing things that we had far too little, or even no, reason to do.

Using the language of reasonableness here may draw our thoughts back to the negligence standard. And so it should. In the law, acting negligently means acting in a way in which someone would not have acted if they had taken reasonable care. ${ }^{31}$ In common parlance, acting negligently means something simpler. It means simply acting without taking reasonable care. The difference between the two ideas is interesting and worthy of our attention. But it is not what concerns us here. What concerns us here is the 'reasonable care' standard that is common to both the legal and the extra-legal version. Is this fundamentally a justificatory standard or an excusatory one? Part of the attraction of the negligence standard, as a device for the law, is precisely its plasticity on this front. 'Reasonable care' may be interpreted to mean 'such care as leads one to reasonable action'. That makes it a quasi-justificatory standard. Or it may be interpreted to mean 'such care as one might reasonably be minded to take', where this is consistent with doing something unreasonable, thanks to reasonable misjudgment, reasonable

${ }^{30}$ Although Rawls gave it a meaning much more idiosyncratic than I have in mind: see his 'Kantian Constructivism in Moral Theory', Journal of Philosophy 77 (1980), 515 at 528-30.

31 Thus the so-called 'duty of care' in the law of torts is not exactly a duty to take care. It is a duty not to act as one would if one did not take care. Ori Herstein put me right on this point in his 'Responsibility in Negligence: Why the Duty of Care is not a Duty "To Try", Canadian Journal of Law and Jurisprudence 23 (2010), 403 at 412-4, rightly criticizing my analysis in 'Obligations and Outcomes in the Law of Torts' in Peter Cane and John Gardner (eds), Relating to Responsibility: Essays for Tony Honoré (Oxford: Hart Publishing, 2001). Pace Herstein, I stand by that analysis in other respects. 
temptation, reasonable concern, etc. This makes the standard a quasi-excusatory standard. By and large the law gravitates towards the quasi-justificatory version, but leaves itself some latitude to make quasi-excusatory allowances for error, for example for less than perfect expertise or skill or resilience. We can all think of negligence cases in which such allowances were made. ${ }^{32}$ We may worry that the allowances are hard to marshal into settled rules, or at any rate that the law has failed so to organise them. For someone worried about so-called 'legal certainty' that is a problem with the negligence standard. For most of the law's purposes, however, the standard's plasticity is a distinct selling-point. The negligence standard allows for quasiexcusatory allowances to be made ad hoc, in response to particular concatenations of facts, without having to generalise. Indeed the central role that modern tort law has found for the negligence standard owes a lot to the space that the standard leaves for unruly responses to particular concatenations of facts, not only in the making of quasi-excusatory allowances, but in various other ways as well. The negligence standard helps to block the pesky transformation of questions of fact, including questions about what we have most reason to do or think or feel or want, into questions of law, governed by rules that treat only selected features of the case as determining the answer. ${ }^{33}$ The quasiexcusatory cases are good examples. Why are quasi-excusatory arguments allowed to figure in some negligence cases but not in others? There is, by design, very little law on the subject.

32 Miscellaneous common-law examples: McHale v Watson (1966) 115 CLR 199; Mullin v Richards [1998] 1 WLR 1304; Surtees v Kingston upon Thames Borough Council [1992] 2 FLR 559; Cook v Cook (1986) ALR 353; Bolam v Friern Hospital Management Committee [1957] 1 WLR 582; arguably, because very close to the borderline, Roe v Minister of Health [1954] 2 QB 66.

33 See my lengthy discussion in 'The Many Faces of the Reasonable Person', Law Quarterly Review 131 (2015), 563. 
You may wonder why I have recently started to add the prefix 'quasi' in front of the words 'justificatory' and 'excusatory'. Here is the explanation. When someone claims to have taken reasonable care, they may of course be asserting that they were justified or excused in what they did. But sometimes they are saying something a bit different. They are denying that any justification or excuse is called for. They are saying that they did nothing wrong, and so don't have anything to justify or excuse. In that case, what would otherwise count as either a justification or an excuse for wrongdoing has instead been anticipated in the very ingredients of the wrong. Although non-negligence sometimes serves as a distinct legal defence, justificatory or excusatory, to some legal wrong that does not have negligence as an ingredient, the negligence standard is often incorporated by the law into the ingredients of the wrong. Questions that might, outside the law, be treated as arising at the stage of justification or excuse ('Why were you on the wrong side of the road anyway?' 'Why didn't you get a second opinion like I suggested?' 'What was the big hurry?' etc.) are transferred over into the determination of whether a wrong (a tort, a breach of contract, etc.) was committed by the defendant in the first place.

The explanation for this transfer is not straightforward. I will mention some aspects of it in the final section of this lecture. The explanation does not, however, make much difference to the point that I am currently developing. Whether or not incorporated into the ingredients of the wrong, the negligence standard is a reasonableness standard. One may invoke it in the course of justifying or excusing a wrong or in the course of denying that one committed a wrong. Either way one displaces the charge of negligence by pointing to the adequacy of one's reasons and that means explaining oneself in the currency of reasons. As soon as one explains oneself in the currency of reasons, one holds oneself out as having been basically responsible. If the explanation points to reasons that one actually had, either reasons for one's action or reasons for taking oneself 
to have reasons for that action, one was indeed basically responsible for the action. Possibly the reasons will turn out to have been adequate to acquit one of negligence, or possibly not. That is irrelevant. One is basically responsible either way, just in virtue of the fact that one was answerable to reasons in respect of the action. One's basic responsibility is confirmed, therefore, by the mere fact that the question of one's negligence arose. It did not depend on one's actually having been negligent. To adapt a terminology often favoured by lawyers, basic responsibility is basically strict responsibility. Negligence is an added extra.

\section{ASSIGNING RESPONSIBILITY FOR NEGLIGENCE}

From the fact that basic responsibility is basically strict responsibility it does not follow, of course, that legal liability should likewise be basically strict liability. That further claim, if sound, lies a long way down the road. ${ }^{34}$ Its soundness depends on what the ingredients of various legal wrongs should be, and on which justifications and excuses, if any, should be available to those who commit them. Possibly (although I doubt it) those who are not at least negligent should never face legal liability, for every unintentional legal wrong should either have negligence as an ingredient or non-negligence as a defence. If that is so, the explanation has nothing to do with any limit on our basic responsibility for our actions. There is no metaphysical limit in the immediate neighbourhood. If there is a limit, it is a political one. It concerns the principles on which assignable responsibility should be assigned to us by the law.

To help with further reflection on this point, consider the following remark by Neil Levy:

${ }^{34}$ You will hear echoes here of Tony Honoré's famous 'Responsibility and Luck', Law Quarterly Review 104 (1988), 530, which has influenced me greatly on the topic of this lecture and on many other topics besides. 
It is only reasonable to demand that someone perform an action if performing that action is something they can do rationally; that is, by means of a reasoning procedure that operates over their beliefs and desires. But what agents can do rationally in this sense is a function of their internalist reasons [i.e. reasons they are aware of, or could become aware of thanks to other reasons they are aware of]. ${ }^{35}$

I have various quarrels with what Levy says here, and with further conclusions that he draws. But here is something that he gets exactly right. Where negligence is concerned, the principal question is about what it is reasonable to demand. Some demands we make of basically responsible agents are unfair or unjust demands. Others are ineffective. Yet others are a sledgehammer to crack a nut. There are many possible lines of objection to the demands we make of each other. The point is that these are all lines of objection that are addressed to $u s$ as the demanders. They presuppose that there is someone who is doing some demanding of the agent, such that the question of the unfairness or stupidity of doing that demanding can arise. In the relevant demands, the agent may of course mistakenly be held to be basically responsible, or she may mistakenly concede her own basic responsibility. Such a mistake may indeed be unfair or stupid on the part of the person making it. But a person's actually being basically responsible for an action, say an action that they did not know they were performing, is not the kind of thing that can be unfair or stupid. Nobody assigns basic responsibility to them, so there is nobody who is being unfair or stupid, let alone unreasonable, in connection with their possession of it. Basic responsibility is simply a fact of human life, such that those who lack basic responsibility are lacking something which, as human

35 Levy, Hard Luck: How Luck Undermines Free Will and Moral Responsibility (Oxford: Oxford University Press 2011), 128. 
beings, they ought to have. ${ }^{36}$ You'll see from that formulation that I don't mean basic responsibility to be somehow a value-free fact of human life. (Are there any?) As I said before, it is valuable to be basically responsible inasmuch as being basically responsible represents the partial achievement of one's human ergon. The point is only that our being basically responsible is not subject to certain types of evaluations. We cannot intelligibly complain, for example, that basic responsibility is unfairly distributed, such that I keep finding myself basically responsible for actions that I did not know I was performing. Nobody distributes it and so the question of the fairness of its distribution does not arise.

When parents point out to their children that 'life isn't fair', I hope they don't mean to suggest that life is unfair. I hope they mean to suggest that it's a mistake - a category mistake - to hold life up to the light of fairness. People can be unfair; so can institutions; so, perhaps, can societies. ${ }^{37}$ But people and institutions and so on can qualify as unfair, or for that matter as stupid, intolerant, mean-spirited etc., only inasmuch as they are agents, capable of responding wrongly to reasons. What is called for is precisely basic responsibility. Only a basically responsible agent can be unfair, stupid, intolerant, and so on. Life cannot be unfair, stupid, intolerant, etc., for life is not an agent. Thinking

${ }^{36}$ For some excellent unpacking of these points and their implications, on a much wider philosophical front, see Angela Smith, 'On Being Responsible and Holding Responsible', Journal of Ethics 11 (2007), 465.

${ }^{37}$ Friedrich Hayek invested much in the idea that societies are not agents, and thus cannot themselves be charged with injustice/unfairness: Law, Legislation, and Liberty, Volume 2: The Mirage of Social Justice (London: Routledge and Kegan Paul 1976), ch 9. I tend to agree. Yet Hayek paid too little attention to the obvious next point that there can be injustice in the way in which people and institutions, who clearly are agents, respond to bad social conditions. This is what we normally mean when we speak, somewhat elliptically, of 'social injustice'. We do not need to think of society as an agent in order to do it. 
of life as an agent, like thinking of luck as an agent, is as instance of what Ruskin branded 'the pathetic fallacy.' 38

Inasmuch as Levy is concerned with the role of negligence in responsibility, then, it cannot be basic responsibility that he has in mind. It must be assignable responsibility. $\mathrm{He}$ is arguing - now without any category mistake - that it is unreasonable to assign assignable responsibilities to people which are such that they could fail in them, or could retroactively be held to have failed in them, without any negligence on their part. As a general proposition that strikes me as far-fetched. We know, because I already pointed out, that it is sometimes true that the negligence standard is incorporated into the ingredients of the wrong, such that, if one was not negligent, one did nothing wrong and one has nothing to justify or excuse oneself for. But there are also cases, as I explained, in which one offers a justification or excuse for something one did wrong, a justification or excuse that centres on the fact that one was not negligent in doing it. For that to be possible, there must be a possibility of wrongs that do not have negligence as an ingredient. There must, to put it another way, be possible assignable responsibilities that do not pass Levy's test - responsibilities, for example, for seeing to it that the parcel will actually arrive today and did actually arrive today, never mind when one thought it would arrive and what led one to think that and how reasonable it was to think that, etc. Maybe such 'strict' responsibilities are always somewhat unfairly assigned to those who have them. But as I said before, that simply points to the need for a suitably strong case for assigning them, one that suffices to overcome the objection of unfairness.

And in fact, it is hard to see the unfairness in the assignment of strict responsibilities as such. It all depends on what one thinks the consequences are going to be of failing in them. Maybe Levy, for example, is tending to think of punishment, condemnation,

38 Ruskin, Modern Painters, Volume III (New York: John Wiley 1863), ch 12. 
resentment, and all that blaming jazz. But these blaming cases are exactly the cases in which one's justifications and excuses for failing in one's responsibilities as a responsible agent should be listened to, and in suitable instances regarded as exonerating. These cases are not the right place to begin; something has gone badly wrong with our priorities if they are where we look first when we think about responsibility. ${ }^{39}$ We should begin with apology, reparation, and restitution, and the complex psychology of blameless but responsible agency that Bernard Williams discussed under the heading of 'agent-regret'. ${ }^{40}$ It may sometimes be unfair for people to be forced to apologise, to have damages extracted from them, to be criticised for the paucity of their feelings, and so on. But is it also unfair or otherwise rationally questionable, do you think, for them to volunteer their apologies, to insist on paying for the damage, to merely rue their part in the day's events and so forth? If that doesn't seem so unfair, could the explanation be that the problem is not, after all, with the strict responsibilities themselves, but with the clumsy way in which the normative consequences of failure in such responsibilities are managed by others? Could it be too much heavy-handedness in the way the responsibilities are identified, marked, and upheld, rather than the responsibilities themselves?

To see if you think that the problem is with the responsibilities themselves, ask yourself this. Ask yourself whether you regard it as unfair that I should be the one who owes you an explanation in the currency of reasons, that I should be the one who owes you a justification or excuse, for what I did to you. If I do sometimes owe that much to you, then my blameless acts are already capable of landing me in a tricky position. They are capable of landing me in the position in

39 J.R. Lucas, 'The Ascription of Actions', available at http://users.ox.ac.uk/ 〜jrlucas/ascript.html (accessed 20 August 2016 and held on file).

40 Williams, 'Moral Luck', Proceedings of the Aristotelian Society Supplementary Volume 50 (1976), 115 at 123-7. 
which I should justify or excuse myself to you, and hence assert my blamelessness. Is that unfair? Not, it seems to me, where the assignable responsibility was mine and I was basically responsible for failing in it. Being the one to answer for failures in your assignable responsibilities goes with the territory of being a rational creature. Pace Levy, I do not owe a justification or excuse for 'an action [only] if performing that action is something [I] can do ... by means of a reasoning procedure that operates over [my] beliefs and desires. ${ }^{41}$ Rather, that this action was the best I could manage given my beliefs and desires, and given what led me to have those beliefs and desires, is the very thing that I will cite in making my justification or excuse. My basic responsibility and my assignable responsibility for what I did are both taken for granted when my justification or excuse - say my argument that I was not negligent - is put on the table.

You may say that the conclusion here is not exactly what I promised. Fundamentally, as it turns out, the negligence standard belongs neither to the conditions of basic responsibility nor to the conditions of assignable responsibility. It belongs to the world of justification and excuse that opens up once responsibility, in both senses, is established. But I'm not sure that I promised otherwise. I think I promised to conclude that, inasmuch as the negligence standard belongs to the conditions of responsibility at all, it belongs to the conditions of assignable responsibility, not to the conditions of basic responsibility. And that is indeed our conclusion. When the question of negligence comes up in connection with responsibility - as opposed to in connection with justification or excuse - it comes up under the heading of assignable responsibility. It bears on whose responsibility it is to do which things, always assuming that all involved are basically responsible for their actions. Do I have the assignable responsibility in law not drive into the path of your car? No. My

${ }^{41}$ Levy, Hard Luck, n35 above, 128. 
responsibility, at most, is not to do so negligently. Do I have the assignable responsibility in law not to leave your gas boiler poorly ventilated after I service it? Quite possibly. The case is different from the first. It could well be a breach of statutory duty case rather than a negligence case and the responsibility assigned to me by law could well be strict. But there is no doubt that I am basically responsible for my failure either way. Negligent or not, and ultimately legally liable or not, it falls to me, the benighted gas installer, to explain myself in the currency of reasons. It is no obstacle to my being in this position that, thanks to some fault in the venting kit or failure in my measurement gear, I wasn't to know what I had done until it was too late to have avoided it. That is my explanation. I was the gas installer; it was my job; my failure is mine to account for, subject only to my possessing the basic human ability to account for it.

\section{NEGLIGENCE AND LEGAL POLICY}

Why might the law sometimes assign us strict responsibilities and sometimes negligence-limited responsibilities? The explanation is political, not metaphysical. Sometimes, as in the case in which I drive out in front of your car, we are both in the same role so far as the law is concerned. We are both drivers and we have, fundamentally, the same responsibilities to each other. These include the responsibility not to cause accidents. But who caused this accident? That, alas, is not so clear. Or rather, insofar as it is clear, that is because of a rule that we inherit mainly from the law. It is a rule that the law uses to attach the (legally relevant) causation of accidents to particular drivers, and it attaches that causation according to negligence. That rule is not, of course, the only rule in play. Things are a bit more complicated. There are various rules of res ipsa loquitur that allow negligence to be deemed when certain other rules of the road, legal and otherwise, are violated. And there are various rules in the Road Traffic Act and the Highway Code and custom among road users 
on which the identification of negligence may turn. Yet the central organising rule remains the negligence rule. It is needed because, without it, the situation of colliding drivers is very often too symmetrical to allow assignable responsibility, in respect of the avoidance of particular accidents, to be assigned. Even when all the more specific rules of the road are considered, often we do not have enough to determine who, for the purpose of liability to pay for the damage of the other, was the cause of the accident. The law's central rule, it seems to me, simply assigns the assignable responsibility, hence the role of accident-causer in law, to whichever of the two drivers was negligent, building the negligence in turn on failure to observe various other rules of the road, some legal, some not, about the significance of painted lines, signage, indicator lights, speed, road position, etc.

This is a common arrangement in the modern law of torts not only in the traffic case, but more generally. In other cases, however, the law may reflect an asymmetry of roles. Gas engineers and the householders for whom they provide boiler repairs do not need the negligence standard to differentiate them. They are already differentiated by the fact that only one of them is a gas engineer (or, in derivative cases, holds himself out as a gas engineer) and the law can make that differentiation without waiting to see how either person handles the interaction between them. It can assign a strict responsibility to the engineer for ensuring that the boiler is adequately ventilated. Should it do so? Many considerations including the extent of the hazard from poor ventilation, the difference in relative expertise between typical gas engineers and their typical customers, the existence of a licensing and certification scheme, the availability of professional indemnity insurance, the availability of carbon 
monoxide alarms, and so forth, bear on the choice of arrangements for assigning responsibility. ${ }^{42}$

It has not been my aim here to defend the use of the negligence standard in driving cases and the rival 'strict' standard in boiler repair cases. Indeed it has not been my aim here to defend the use of the negligence standard in some cases and not in other cases. My aim has been to show you what kind of considerations bear on the choice. Not only are considerations of this kind the ones that matter when assignable responsibility is assigned by the law. Considerations of this kind are also the ones which bear on who has assignable responsibility even before anybody, including the law, assigns it. Such considerations bear, in other words, on the role that the negligence standard plays in everyday life outside the law, as well as in the law.

I hope that you can now see what kind of considerations they are. They are, in the widest sense, political considerations. They relate to the desirability or appeal or merit or attractiveness of the arrangements whereby some people have responsibility for some things, and others have responsibility for others. They point to the fairness, the efficiency, or more generally the reasonableness, of responsibilities being carved up in that way, or in some other way. They do not relate to the tragedy of the human condition or the impossibility of our escape from our rational nature. They do not belong to the metaphysics of basic responsibility. They belong instead to the politics of assignable responsibility.

42 For current English law on the subject, which I do not purport to be summarizing in the text, see the Gas Safety (Installation and Use) Regulations 1998 and the Enterprise and Regulatory Reform Act 2013, s69(3). Under the 2013 Act tort liability in respect of gas installation, and other health and safety matters, has substantially shifted away from the strict liability model that I sketched and towards a negligence model akin to the one prevailing on the roads. That is an object lesson in the politics of assignable responsibility: compared with strict liability, negligence liability is 'deregulation'. 